\title{
Four Years Analysis of Cancer Genetic Clinics Activity in France from 1994 to 1997: A Survey on 801 Patients
}

Hagay Sobol $^{1, \#}$, Yves-Jean Bignon ${ }^{2}$, Catherine Bonaiti ${ }^{3}$, Jean Cuisenier ${ }^{4}$, Christine Lasset ${ }^{5}$, Alain Lortholary ${ }^{6}$, Catherine Noguès ${ }^{7}$, Dominique StoppaLyonnet $^{8}$, François Eisinger ${ }^{1, \#}$ and the French Cooperative Network/Groupe Génétique et Cancer de la Fédération Nationale des Centres de Lutte Contre le Cancer ${ }^{9}$

${ }^{1}$ Département d'Oncologie Génétiquel INSERM E 9939, Institut Paoli-Calmettes, 13009 Marseille, France

${ }^{2}$ Unité de Génétique Oncologique/INSERM CRI 9502, Centre Jean Perrin, 63011

Clermont Ferrand, France

${ }^{3}$ INSERM U 351, Institut Gustave Roussy, 94805 Villejuif, France

${ }^{4}$ Consultation d'Oncogénétique, Centre

Georges-François Leclerc, 21034 Dijon,

France

${ }^{5}$ Unité de Génétique Epidémiologique des Cancers, Centre Léon Bérard, 69373 Lyon, France

${ }^{6}$ Consultation d'Oncogénétique, Centre Paul Papin, 49033 Angers, France

${ }^{7}$ Unité d'Oncologie Génétique, Centre René Huguenin, 92211 Saint-Cloud, France

${ }^{8}$ Unité de Génétique Epidémiologique, Institut Curie, 75231 Paris, France ${ }^{9}$ Fédération Nationale des centres de Lutte Contre le Cancer (FNCLCC), 75654 Paris, France

\footnotetext{
\# Correspondence: F. Eisinger or H. Sobol, Département d'Oncologie Génétique, de Dépistage et de Prévention/ INSERM E 9939, Institut Paoli-Calmettes 232 Bd de Sainte Marguerite, 13273 Marseille cedex 9, France
}

ABSTRACT: AIM: In order to evaluate the characteristics and the evolution of cancer genetics activity in France, a survey was conducted at the national level during a period of 4 years from 1994 to 1997 through the French Cooperative Network, a multidisciplinary group formed to investigate inherited tumors.

METHOD: A questionnaire was sent to all the 29 French non-specialized cancer genetic clinics to evaluate activity during a period of 4 consecutive weeks each year from 1994 to 1997 . Items concerning the cancer genetic clinics, the consultees and the types of consultation were explored.

RESULTS: A total number of 801 consultees were seen during the period of analysis. Some prominent characteristics of patients attending cancer genetic clinics were found. The majority of these are women $(88 \%)$, and the mean age of consultees is 48 years. Fifty five percent of consultees are affected with cancer, and breast (personal and/or family history) is the most frequent site involved (63\%). A genetic predisposition is certain or likely in about $53 \%$ of cases and unlikely in only $13 \%$ of consultations. The majority of consultations are devoted to new families $(71 \%)$. The mean duration of consultations is 50 minutes, but $40 \%$ have a duration of at least 1 hour. Variations of several parameters during the 4 years period were observed and analyzed. Finally, since duration of consultations (more or equal to 1 hour) and personal or family history of breast/ovarian cancer appeared as pivotal elements in our study and consequently may affect the organization of clinics and the structuring as well as the evolution of cancer genetic activity in France, we analyzed more precisely the factors significantly associated with these 2 elements.

CONCLUSION: Study compliance was fair $(60 \%$ of centers) and these results give a good measure of cancer genetic activity in France. The variation of parameters from one year to another may reflect modifications in medical practice (medical orientation rather than research focus and content of cancer genetic clinics) 
and/or scientific breakthroughs in cancer genetics such as identification of genes predisposing to cancer.

KEYWORDS: Cancer genetics, breast cancer, colon cancer, consultation, BRCA1, BRCA2, genetic testing, medical organization, screening, prevention

\section{INTRODUCTION}

Cancer Genetics is a fast moving field. Since the early 1980's more than 30 genes predisposing to cancer have been identified, and some clues about hereditary carcinogenesis as well as information about natural history of hereditary carcinomas are now available [1-4]. The major challenge is now the use of this scientific knowledge in medical practice in terms of diagnosis, genetic testing and clinical management [5-8]. As hereditary tumors represent about $5 \%$ of cancers, for instance, more than 1500 new cases of breast cancer diagnosed every year in France [7], individuals at high genetic risk represent a large population that may require specific medical interventions. In France, the first cancer genetic clinics were set up between 1986 and $1989[9,10]$ and to date, clinics are working in the 20 cancer centers and in public hospitals as well as in some private institutions $[7,11]$. These family cancer clinics are organized in the frame of a multidisciplinary group, the French Cooperative Network, formed in 1991 to investigate inherited tumors and to develop protocols for their screening and treatment, to establish recommendations to organize the clinical activity and to promote clinical and/or biological research programs [7,10-13].

The study of characteristics and of the evolution of cancer genetics activity at the national level may help to improve organisation of consultations and to anticipate the expectations of patients and physicians, as well as in the setting up of specific research programs. Here we present a national survey analyzing the cancer genetic activity during a period of four consecutive weeks conducted annually from 1994 to 1997.

\section{MATERIAL AND METHODS}

\section{The French Cooperative Network}

The French Cooperative Network/Groupe Génétique et Cancer belongs to the French National Cancer Center Network (FNCLCC) covering 20 comprehensive cancer centers with a homogeneous geographical distribution [7]. For instance, every year, about 14000 new breast carcinomas, corresponding to almost 55\% of all the cases diagnosed in France, are managed at least partially in these centers. A family cancer clinic has been set up at each of these institutes. In addition, cancer genetic clinics were set up in other types of medical institution (University hospital and private institute).

\section{Procedure}

To evaluate the activity in cancer genetics at the national level, a questionnaire was sent to the 29 cancer genetic clinics existing in 1994 (excluding the 14 clinics with only specialized activity concerning rare inherited syndromes). Each physician had to fill in a questionnaire concerning all patients seen during a period of 4 consecutive weeks of activity (in 1995 only, the study was conducted over a longer period of 6 weeks including 2 weeks of vacation with a dramatic reduction or almost no clinical activity, corresponding thus, to a full activity of 4 weeks). The study was conducted during the second quarter of each of the years from 1994 to 1997.

Items were explored about: $i$. the cancer genetic clinics (number of patients seen, type of institute where the cancer clinics take place, geographical area associated with the clinics); $i$. the consultees (age, gender, diagnosis if affected with a tumor, genetic status, referral pathway); iii. the type the consultation (new family, new individual from a known family, follow up of a known individual, duration, prevention and screening advice, medical and pathological record collection, blood sample collection, inclusion of patients in research protocols). Origin of cancer genetic clinics and results from each consultation were anonymized. 


\section{Statistical analysis}

General consideration of data: Only specific answers were considered for analyses. Thus, for each item, «absence of answer or don't know» were discarded from the study. Therefore, the number of consultations analyzed, according to the different items, will not be the total of 801 patients reported.

Univariate analysis: Univariate comparisons were carried out with Pearson Chi-square tests for qualitative data, and analysis of variance (ANOVA) for quantitative data. Statistical analyses were performed with SPSS Statistical Software Package Version 8.0. To compute the odds ratio EPI-INFO version 5.01 package was used.

Multivariate analysis: A logistic regression analysis was then carried out. All significant parameters at the level 0.05 were tested using a forward stepwise Wald method (SPSS Statistical Software Package Version 8.0).

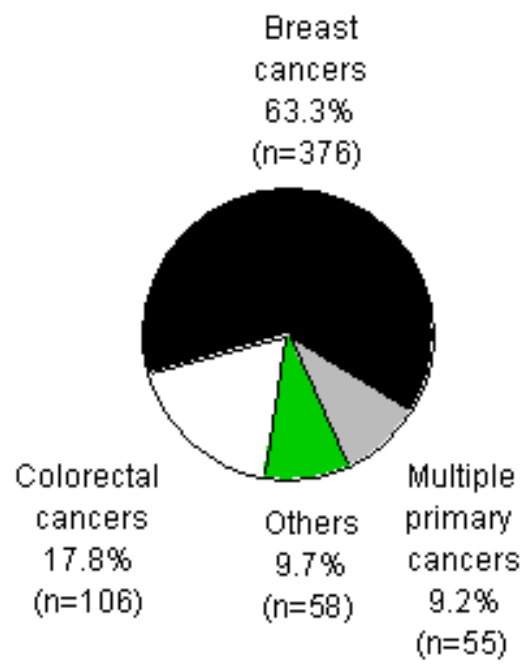

Fig. 1. Type of cancers (personal and/or family history) seen in cancer genetic clinics during the 4-year period of analysis.

Table 1

Cancer genetic clinics framework

\begin{tabular}{llccccc}
\hline Years & $\mathrm{N}$ & Cancer Center (\%) & Public Hospital (\%) & Private Institution (\%) & Others (\%) & $\mathrm{p}$ \\
\hline 1994 & 199 & $170(85.4)$ & $9(4.5)$ & $5(2.5)$ & $15(7.5)$ & \\
1995 & 232 & $191(82.3)$ & $10(4.3)$ & $8(3.4)$ & $23(9.9)$ & \\
1996 & 135 & $119(88.1)$ & $2(1.5)$ & $7(5.2)$ & $7(5.2)$ & \\
1997 & 229 & $165(72.1)$ & $38(16.6)$ & $17(7.4)$ & $9(3.9)$ & \\
Total & 795 & $645(81.1)$ & $59(7.4)$ & $37(4.7)$ & $54(6.8)$ & $<\mathbf{0 . 0 0 0 0 1}$ \\
\hline
\end{tabular}

$\mathrm{N}=$ number of consultees; $\mathrm{p}=$ trend

Table 2

Gender of consultees

\begin{tabular}{llccc}
\hline Years & N & Male (\%) & Female (\%) & p \\
\hline 1994 & 202 & $35(17.3)$ & $167(82.7)$ & \\
1995 & 232 & $18(7.8)$ & $214(92.2)$ & \\
1996 & 135 & $13(9.6)$ & $122(90.4)$ & \\
1997 & 231 & $29(12.6)$ & $202(87.4)$ & $\mathbf{0 . 0 1 7}$ \\
Total & 800 & $95(11.9)$ & $705(88.1)$ & \\
\hline
\end{tabular}

$\mathrm{N}=$ number of consultees; $\mathrm{p}=$ trend 


\section{RESULTS}

\section{Compliance}

Of 29 institutes to which a questionnaire was sent, $20(69 \%)$ participated in the study in 1994, $13(45 \%)$ in 1995, 11 in $1996(38 \%)$ and 25 $(86 \%)$ in 1997 . The mean participation rate was 17 clinics/year $(60 \%)$.

\section{Characteristics of cancer genetic clinics}

Number of patients seen: A total of 801 patients was seen during the survey period (4 weeks, equivalent to an activity of 1 month, during 4 consecutive years). The mean number of patients/cancer clinic/month was 10.2 in 1994,
17.8 in 1995, 12.3 in 1996 and 9.2 in 1997. The mean number of patients/cancer clinic/month was 12.4 .

Type of institution where the clinics take place (Table 1): Data were not available in 1994 . Of 795 patients seen from 1995 to 1997, a large proportion of $675(81.1 \%)$ attended cancer genetic clinics in Cancer Centers, 59 (7.4\%) in Public Hospitals, 37 (4.7\%) in Private Institutions and $54(6.8 \%)$ in other frameworks.

A significant change in the distribution of patients with reference to the type of institution where the clinic was set up was observed during the 4 years period $(\mathrm{p}<0.00001$; Table 1$)$. Although Cancer Centers account for a majority of consultees, during this period, an increasing proportion of patients has been seen in Public

Table 3

Genetic status

\begin{tabular}{llcccc}
\hline \multicolumn{5}{c}{ Genetic predisposition } \\
\hline Years & $\mathrm{N}$ & Certain or likely $(\%)$ & Possible or discussed $(\%)$ & Unlikely (\%) & $\mathrm{p}$ \\
\hline 1994 & 183 & $88(48.1)$ & $77(42.1)$ & $18(9.8)$ & \\
1995 & 225 & $119(52.9)$ & $75(33.3)$ & $13.8)$ & \\
1996 & 134 & $61(45.5)$ & $55(41.0)$ & $33(14.4)$ & \\
1997 & 226 & $138(61.1)$ & $55(24.3)$ & $100(13.0)$ & $\mathbf{0 . 0 0 5}$ \\
Total & 768 & $406(52.9)$ & $262(34.1)$ & & \\
\hline
\end{tabular}

$\mathrm{N}=$ number of consultees; $\mathrm{p}=$ trend

Table 4

Type of consultation

\begin{tabular}{|c|c|c|c|c|c|}
\hline & & New & New & Follow up & \\
\hline Years & $\overline{\mathrm{N}}$ & family (\%) & individual (\%) & $(\%)$ & $\mathrm{p}$ \\
\hline 1994 & 203 & $153(75.4)$ & & & \\
\hline 1995 & 227 & $163(71.8)$ & $42(18.5)$ & $22(9.7)$ & \\
\hline 1996 & 133 & $96(72.2)$ & $15(11.3)$ & $22(16.5)$ & \\
\hline 1997 & 231 & $150(64.9)$ & $40(17.3)$ & 41 (17.7) & $<0.00001$ \\
\hline Total * & 794 & $562(70.8)$ & & & \\
\hline Total & 591 & 409 (69.2) & 97 (16.4) & 85 (14.4) & \\
\hline
\end{tabular}

* In 1994 data others than « new family » were pooled. $\mathrm{N}=$ number of consultees; $\mathrm{p}=$ trend

Table 5

Blood sample collection

\begin{tabular}{llccc}
\hline Years & $\mathrm{N}$ & Yes $(\%)$ & No $(\%)$ & $\mathrm{p}$ \\
\hline 1994 & 191 & $160(83.8)$ & $31(16.2)$ & \\
1995 & 212 & $170(80.2)$ & $42(19.8)$ & \\
1996 & 125 & $83(66.4)$ & $42(33.6)$ & \\
1997 & 194 & $135(69.6)$ & $59(30.4)$ & \\
Total & 722 & $548(75.9)$ & $174(24.1)$ & $<\mathbf{0 . 0 0 0 1}$ \\
\hline
\end{tabular}

$\mathrm{N}=$ number of consultees; $\mathrm{p}=$ trend 
Hospitals and in Private Institutions.

Geographical area associated with the cancer genetic clinics: As cancer geneticists may have developed consultations in several places other than their main Institution, we have analyzed the geographical area covered by the geneticist (place where patients are seen) and thus associated to the clinics. Of 793 patients for whom the information was available, 659 $(83.1 \%)$ were seen at the main place of work of the geneticist, $40(5 \%)$ were seen in the same city as the refereed clinics but in a different institution, $44(5.5 \%)$ were seen in an institution from the same administrative district, and 50 (6.3\%) were seen in the same administrative region.

\section{Characteristics of consultees}

Gender: Of 800 patients for whom information was available, $705(88.1 \%)$ of consultees were female. However, a change in the distribution of males attending the consultations was seen during the 4 year period ( $p=0.017$; Table 2$)$. In 1995 , a smaller number of male patients was seen compared to $1994 \quad(7.8 \%$ and $17.3 \%$, respectively). Then, a weak but significant trend towards an increasing number of males, reaching $12.6 \%$ in 1997 , was observed. This variation may be associated with scientific "breakthroughs" and consequent new developments in medical practice.

Age: The mean age of 646 consultees, for whom the information was available, was relatively young, at 48 years, with a range from 16 to 85 years.

Disease status: Of 779 patients, 428 (54.9\%) have developed a cancer, meaning that almost half of consultees were not affected.

The type of cancer in patients and/or in the family was then analyzed (Figure 1), but was not mentioned in 1994. Of 595 patients, $376(63.2 \%)$ had a personal and/or a family history of breast/ovarian cancer, $106(17.8 \%)$ a history of colorectal cancer, $55(9.2 \%)$ a history of multiple primary tumors, and $58(9.7 \%)$ had a history of other cancers corresponding mainly to rare situations (MEN 1 or 2, NF1 or 2, Von Hippel
Lindau...). History of breast/ovarian cancer is the major cause of consultation. However, a weak but significant increasing number of cases with history of colon cancer is seen in cancer genetic clinics $(\mathrm{p}=0.030)$ during the 4 years of analysis.

Genetic status: In 406 (52.9\%) of 768 patients for whom information was available, a genetic predisposition to cancer was considered as certain or likely, was possible or discussed in 262 $(34.1 \%)$, and was unlikely in 100 (13\%) (Table 3). Significant variations were seen during the 4-year period. Indications or evaluation of genetic status seem to have become much better established with more cases where a genetic predisposition is considered as certain or unlikely vs. situations where no firm conclusion is reached.

Patients' referral pathway: In 576 (72.9\%) of 790 consultations, patients were referred by a physician, mainly a medical specialist (only 3\% of consultees were referred by a general practitioner), in $97(12.3 \%)$ consultations by a family member, and in 117 (14.8\%) consultations by patients attending the clinics was their own decision or they were referred from a nonmedical source (Figure 2).

\section{Characteristics of consultations}

Types of consultation: From 1994 to 1997, of 794 patients, $562(70.8 \%)$ belonged to families not previously seen in the clinics. From 1995 to 1997, in addition to the "new family item » analysis also documented consultations for a new individual from a known family and those concerning the follow up of a previously seen individual from a known family. Thus, of 591 consultations, $97(16.4 \%)$ were devoted to new individuals from known families, and 85 (14.4\%) consultations to the follow up of an individual previously seen (Table 4). Altogether, during the period of analysis, an evolution of the type consultation was seen $(p<0.00001)$, with a decreasing proportion of consultations of patients from new families and an increasing number of consultations devoted to the follow up of known individuals (in 1994, situations others than new families were pooled). 


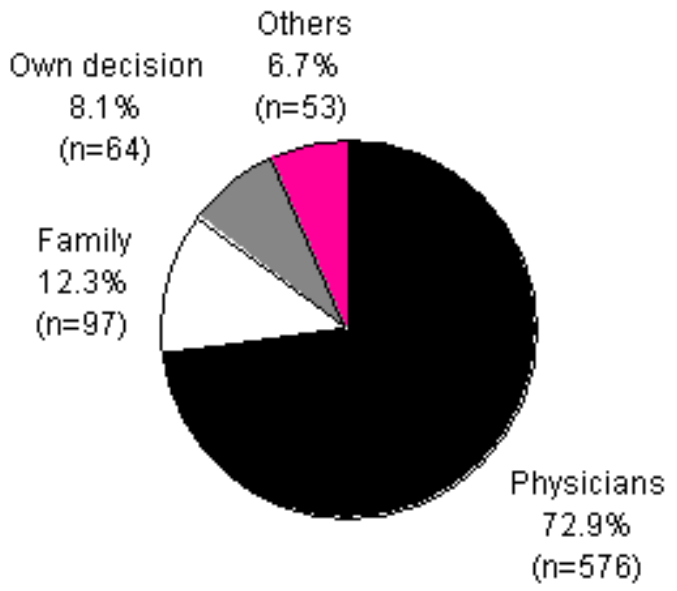

Fig. 2. Patients' referral pathways during the 4-year period of analysis.

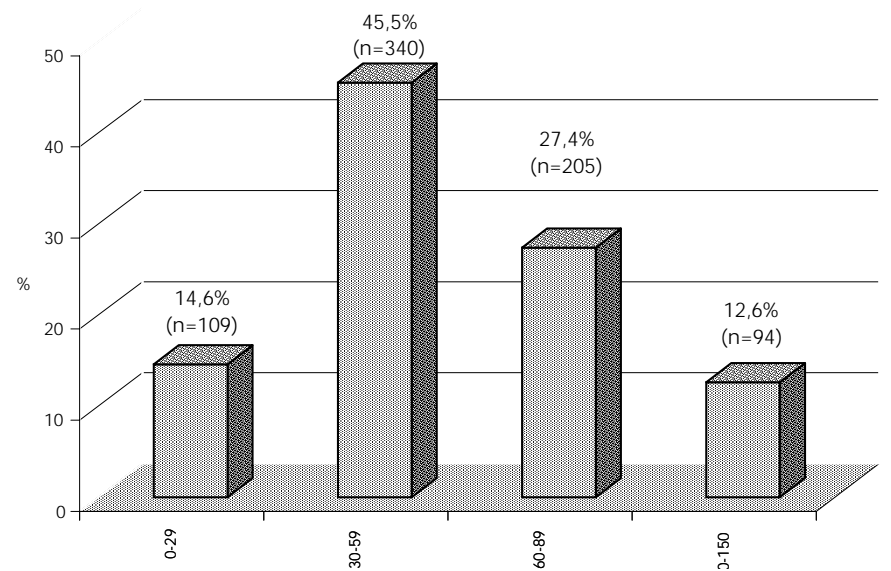

Fig. 3. Duration of consultations during the 4-year period of analysis.

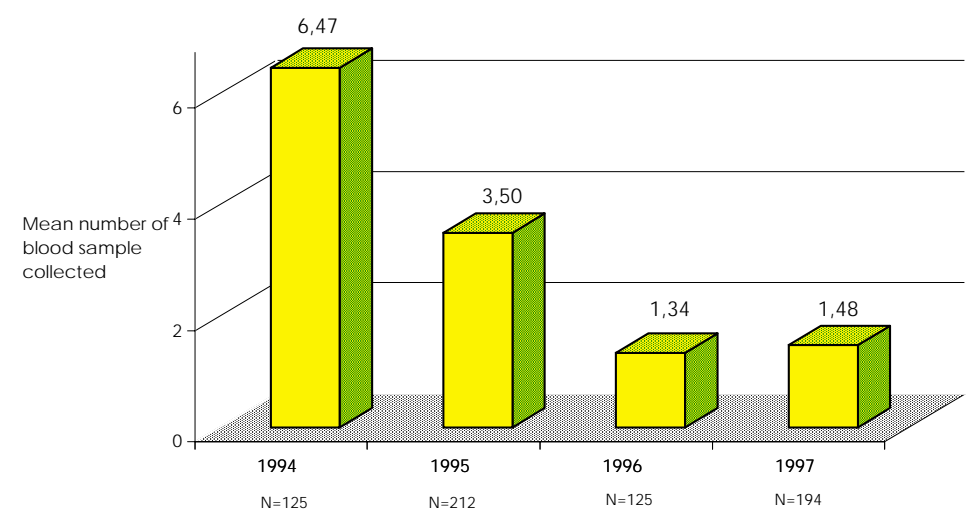

Fig. 4. Mean number of blood samples collected by consultation during the 4-year period of analysis. 
Duration of consultations: Of 748 consultations $109(14.6 \%)$ had a duration of 29 minutes or less, $340(45.5 \%)$ a duration of 30 minutes to 59 minutes, $205(27.4 \%)$ a duration of 60 minutes to 89 minutes, and $94(12.6 \%)$ a duration of 90 minutes to 150 minutes (Figure 3). The mean duration of consultations was 50 minutes. Importantly, 40\% (299) of consultations have a duration of at least 1 hour, and no variation was seen during the 4 years of analysis.

Counseling patients about prevention and screening: Of 784 patients, 583 (74.4\%) were given information about screening procedures. In addition, advice about prevention of cancer (associated or not with genetic predisposition) were given in $224(32 \%)$ of 701 patients, and a variation was seen during the 4 years period with an increasing number of patients counseled $(p=0.007)$. In contrast, no variation was seen about screening advice.

Blood sample collection: Of 722 patients seen in consultations, for 548 (75.9\%) collection of a blood sample was carried out or planned (Table 5), with a mean number of 3 individual samples for each family (the latter information was available for 656 consultations only). A huge variation was observed during the 4 years period: with a decrease in the number of consultations at which a blood sample was collected (Table 5; p < 0.0001), and also in the number of individual samples collected per family, from about 6 to 1 (Figure 4; $\mathrm{p}<0.0001$ ).

Medical and pathological report collection: In $474(67 \%)$ of 707 consultations a medical or a pathological report was collected or required in order to assess the diagnosis of a mean number of 2 family members.

Inclusion of patients in research protocols: Data were available for 3 years only (from 1995 to 1997$)$. Of 579 patients, 118 (20.4\%) were enrolled in research protocols concerning molecular, public health or social science programs. A variation was seen during the period of analysis with an increasing number of patients enrolled (Table 6; $p<0.0001$ ).

\section{Characteristics of consultations with a duration of 1 hour and more}

Since duration appeared as a pivotal element of consultations in terms of structure and organization, and because there was relative stability, during the 4 years of analysis, in the fraction of consultation lasting 1 hour or more, we have analyzed more precisely the factors that may affect this element.

Univariate analysis: Of the 13 factors analyzed, 11 differed significantly between consultations with a duration of at least 1 hour, compared to the others (Table 7). The factor associated with the strongest odd ratio (OR) was the type of consultation (new family). Unexpectedly, the disease status of the patient and the inclusion of patients in research protocols were not discriminant factors affecting duration of consultation.

Multivariate analysis: Of 11 parameters retained in the univariate analysis, 7 were significantly correlated with a duration of one hour or more in the multivariate analysis (Table 8). Consulting a new family was the major element explaining the duration $(\mathrm{OR}=5.8)$. Then, 4 other factors constituted a group with an OR of more than 2: $i$. the need to assess the diagnosis of one or more family members by collecting pathological reports, ii. prevention advice, and iii. the type of tumor: existence of a personal and/or a family history of breast/ovarian

Table 6

Research protocol inclusion

\begin{tabular}{lcccc}
\hline Years & N & Yes $(\%)$ & No $(\%)$ & p \\
\hline 1994 & \multicolumn{5}{c}{ Data non available } \\
1995 & 223 & $37(16.6)$ & $186(83.4)$ & \\
1996 & 131 & $12(9.2)$ & $119(90.8)$ & \\
1997 & 225 & $69(30.7)$ & $156(69.3)$ & \\
Total & 579 & $118(20.4)$ & $461(79.6)$ & $<\mathbf{0 . 0 0 0 1}$ \\
\hline
\end{tabular}


Table 7

Factors associated with a 1 hour or more duration of consultation in decreasing order of OR: univariate analysis

\begin{tabular}{|c|c|c|c|}
\hline Factors (n) & $\begin{array}{c}\text { Duration } \\
\geq 60 \text { minutes }(n)\end{array}$ & $\mathrm{p}$ & $\begin{array}{c}\text { OR } \\
(95 \% \mathrm{CI})\end{array}$ \\
\hline \multicolumn{4}{|l|}{ Type of consultation } \\
\hline New family (527) & $49.1 \%(259)$ & \multirow[t]{2}{*}{$<0.0001$} & 4.37 \\
\hline Known family (221) & $18.1 \%(40)$ & & $(2.94-6.53)$ \\
\hline \multicolumn{4}{|l|}{ Pathological report collection } \\
\hline Yes $(450)$ & $50.4 \%(227)$ & \multirow[t]{2}{*}{$<0.0001$} & 3.70 \\
\hline No (218) & $21.6 \%(47)$ & & $(2.51-5.47)$ \\
\hline \multicolumn{4}{|l|}{ Gender } \\
\hline Female (657) & $42.6 \%(280)$ & \multirow[t]{2}{*}{$<0.0001$} & 2.78 \\
\hline Male (90) & $21.1 \%(19)$ & & $(1.59-4.89)$ \\
\hline \multicolumn{4}{|l|}{ Screening advice } \\
\hline Yes (542) & $45.8 \%(248)$ & \multirow[t]{2}{*}{$<0.0001$} & 2.68 \\
\hline No (192) & $24 \%(46)$ & & $(1.82-3.95)$ \\
\hline \multicolumn{4}{|l|}{ Prevention advice } \\
\hline Yes $(201)$ & $53.7 \%(108)$ & \multirow[t]{2}{*}{$<0.0001$} & 2.17 \\
\hline No (456) & $34.9 \%(159)$ & & $(1.53-3.08)$ \\
\hline \multicolumn{4}{|l|}{ Type of cancer } \\
\hline Breast cancer (349) & $46.7 \%(163)$ & \multirow[t]{2}{*}{$<0.0001$} & 2.15 \\
\hline Others (204) & $28.9 \%(59)$ & & $(1.47-3.17)$ \\
\hline \multicolumn{4}{|l|}{ Geographical area of clinics } \\
\hline Main place of work (616) & $42.7 \%(263)$ & \multirow[t]{2}{*}{0.001} & 1.99 \\
\hline Others (132) & $27.3 \%(36)$ & & $(1.29-3.07$ \\
\hline \multicolumn{4}{|l|}{ Patients' referral pathways } \\
\hline Medical practitioners specialized (517) & $44.5 \%(230)$ & \multirow[t]{2}{*}{$<0.0001$} & 1.88 \\
\hline Others $(231)$ & $29.9 \%(69)$ & & $(1.33-2.66)$ \\
\hline \multicolumn{4}{|l|}{ Cancer genetic clinics framework } \\
\hline Cancer center (597) & $42.4 \%(253)$ & \multirow[t]{2}{*}{0.008} & 1.68 \\
\hline Others (151) & $30.5 \%(46)$ & & $(1.13-2.51)$ \\
\hline \multicolumn{4}{|l|}{ Blood sample collection } \\
\hline Yes $(522)$ & $42.5 \%(222)$ & \multirow[t]{2}{*}{0.042} & 1.47 \\
\hline No $(161)$ & $33.5 \%(54)$ & & $(1.0-2.16)$ \\
\hline \multicolumn{4}{|l|}{ Genetic predisposition } \\
\hline Certain or likely (380) & $44.2 \%(168)$ & \multirow[t]{2}{*}{0.016} & 1.44 \\
\hline Others (363) & $35.5 \%(129)$ & & $(1.06-1.95)$ \\
\hline \multicolumn{4}{|l|}{ Disease status } \\
\hline Cancer (396) & $38.4 \%(152)$ & \multicolumn{2}{|l|}{0.257} \\
\hline No cancer (334) & $42,5 \%(142)$ & \multicolumn{2}{|l|}{ NS } \\
\hline \multicolumn{4}{|l|}{ Research protocol inclusion } \\
\hline Yes $(110)$ & $40.0 \%(44)$ & \multicolumn{2}{|l|}{0.922} \\
\hline No (427) & $40.5 \%(173)$ & NS & \\
\hline
\end{tabular}

Table 8

Factors associated with a 1 hour duration or more of the consultation: logistic regression analysis

\begin{tabular}{lccc}
\hline Factors (N=403) & Adjusted odds-ratio & $95 \%$ CI & $\mathrm{p}$ \\
\hline Pathological report collection & 2.98 & $1.79-4.93$ & $<0.00001$ \\
Framework: Cancer center & 2.12 & $1.18-3.80$ & 0.0117 \\
Screening advice & 1.78 & $1.01-3.13$ & 0.0441 \\
Breast cancer & 2.29 & $1.38-3.82$ & 0.0014 \\
Genetic predisposition certain or likely & 1.72 & $1.04-2.84$ & 0.0317 \\
Prevention advice & 2.48 & $1.43-4.30$ & 0.0011 \\
New family & 5.8 & $3.21-10.48$ & $<0.00001$ \\
\hline
\end{tabular}


cancer. Finally, the remaining two parameters with an OR of more than 1 were screening advice and the existence of a genetic predisposition (certain or likely). In contrast, gender, patient's referral pathways, and blood sample collection were not retained in the multivariate analysis.

\section{Characteristics of consultations for personal and/or family history of breast/ovarian cancer}

Since breast and ovary (personal and/or family history) were the most frequent sites of cancer seen during the 4 years period, the characteristics of consultations for this purpose were analyzed.

Univariate analysis: Of 13 factors analyzed, 8 differed significantly between consultations for breast/ovarian cancer and those for another site (Table 9). Obviously, gender was the most significant factor $(\mathrm{OR}=9.07)$. In contrast, 3 parameters did not differ significantly: research protocol inclusion, prevention advice and pathological record collection.

Multivariate analysis: Of 8 factors significant in the univariate analysis, only 4 were retained in

Table 9

Factors associated with a consultation for a personal history of breast/ovarian cancer in decreasing order of OR: univariate analysis

\begin{tabular}{|c|c|c|c|}
\hline Factors $(n)$ & Breast/ovarian cancer $(\mathrm{n})$ & $\mathrm{p}$ & OR $(95 \% \mathrm{CI})$ \\
\hline \multicolumn{4}{|l|}{ Gender } \\
\hline Female (537) & $68.0 \%(365)$ & $<0.0001$ & 9,07 \\
\hline Male (58) & $19.0 \%(11)$ & & $(4.41-19.04)$ \\
\hline \multicolumn{4}{|l|}{ Cancer genetic clinics framework } \\
\hline Cancer center (472) & $67.2 \%(317)$ & $<0.0001$ & 2.42 \\
\hline Others $(121)$ & $47.1 \%(57)$ & & $(1.45-3.38)$ \\
\hline \multicolumn{4}{|l|}{ Genetic predisposition } \\
\hline Certain or likely (318) & $72.3 \%(231)$ & $<0.0001$ & 2.36 \\
\hline Others (265) & $52.8 \%(140)$ & & $(1.66-3.40)$ \\
\hline \multicolumn{4}{|l|}{ Duration of consultation $\geq 1$ hour } \\
\hline Yes (222) & $73.4 \%(163)$ & $<0.000$ & 2.15 \\
\hline No (331) & $56.2 \%(186)$ & & $(1.47-3.17)$ \\
\hline \multicolumn{4}{|l|}{ Screening advice } \\
\hline Yes (445) & $67.0 \%(298)$ & 0.002 & 1.84 \\
\hline No (141) & $52.5 \%(74)$ & & $(1.23-2.75)$ \\
\hline \multicolumn{4}{|l|}{ Blood sample collection } \\
\hline Yes (385) & $67.3 \%(259)$ & 0.023 & 1.57 \\
\hline No (143) & $56.6 \%(81)$ & & $(1.04-2.38)$ \\
\hline \multicolumn{4}{|l|}{ Patients' referring pathways } \\
\hline Medical practitioners specialized (410) & $66.1 \%(271)$ & 0.029 & 1.49 \\
\hline Others $(185)$ & $56.8 \%(105)$ & & $(1.02-2.15)$ \\
\hline \multicolumn{4}{|l|}{ Type of consultation } \\
\hline New family (408) & $63.2 \%(258)$ & $<0.0001$ & \\
\hline New individual (95) & $48.4 \%(46)$ & & \\
\hline Follow up (85) & $80.0 \%(68)$ & & \\
\hline \multicolumn{4}{|l|}{ Prevention advice } \\
\hline Yes (173) & $58.4 \%(101)$ & 0.053 & 0.69 \\
\hline No (366) & $66.9 \%(245)$ & NS à $5 \%$ & $(0.47-1.02)$ \\
\hline
\end{tabular}

Table 10

Factors associated with a consultation for personal or family history of breast/ovarian cancer: logistic regression

\begin{tabular}{lccc}
\hline Factors $(\mathrm{N}=487)$ & Adjusted odd-ratio & $95 \%$ CI & $\mathrm{p}$ \\
\hline & & & \\
Gender: Female & 9.68 & $4.51-20.73$ & $<0.00001$ \\
Genetic predisposition certain or likely & 2.91 & $1.90-4.45$ & $<0.00001$ \\
Framework: Cancer center & 2.28 & $1.38-3.75$ & 0.0012 \\
Duration of consultation $\geq 1$ hour & 1.86 & $1.20-2.87$ & 0.0052 \\
\hline
\end{tabular}


the multivariate analysis (Table 10). The most important was gender $(\mathrm{OR}=9.68)$, and then, the existence of a genetic predisposition to cancer (certain or likely), the type of institute (Cancer center) and the duration of the consultation (1 hour or more).

\section{Reconstructing a one year period of cancer genetic activity at the national level in France}

Cancer genetic activity whatever the cancer site involved: According to a French standard of 46 working weeks a year, and of data on activity from the present study, an average of 3500 consultations are carried out every year in France. Of these, $2500(3500 * 70.8 \%)$ are devoted to new families, whatever the cancer site involved. Finally, in about $1300(2500 * 52.9 \%)$ of these consultations a genetic predisposition is considered as certain or likely.

Cancer genetic activity involving breast/ ovarian cancer: At the national level every year, in about $2200(3500 * 63.3 \%)$ consultations breast/ovarian cancers are involved. Of these, $1500(2200 * 68.6 \%)$ are devoted to new families. Finally, in about $900(1500 * 59.3 \%)$ of these consultations a genetic predisposition is considered as certain or likely.

\section{DISCUSSION}

Compliance with the study was fair, with about $60 \%$ of genetic cancer clinics participating during the 4-year period of analysis. This survey gives a relatively good measure of what cancer genetic activity is in France. A total of 801 consultees was analyzed, corresponding to 12 patients seen by each center during about 1 month of activity. Based on these results, it is estimated that at the national level, about 3500 consultations would be undertaken in familial cancer clinics every year in France. Of these, 2500 would be devoted to new families whatever the cancer site involved, and in about 1300 of these consultations a genetic predisposition would be considered as certain or likely. Considering only consultations involving breast/ovarian cancer, about 2200 consultations would be carried out every year. Of these, 1500 would correspond to new families, and in about 900 of these consultations a genetic predisposition would be considered as certain or likely. Since the majority of patients attend cancer genetic clinics from Cancer centers $(81 \%)$, and since almost $55 \%$ of all breast cancer cases diagnosed in France are managed at least partially in cancer centers [7], considering that a cancer genetic clinic has been set up in all the 20 of the cancer centers, that may explain the prevalence of consultations devoted to breast/ovarian cancer.

Indications for consultation, in a good proportion of cases, are well established. Thus, a genetic predisposition is considered as certain or likely in about $53 \%$ of cases and is unlikely in only $13 \%$ of consultations. The typical consultee is a woman younger than 50 years with a personal or a family history of breast/ovarian cancer whose family was not yet explored the issue of genetic risk. The mean duration of consultations is 50 minutes, and $40 \%$ have a duration of at least 1 hour. This duration may be explained by the content of consultations: such as the establishment of the genealogical tree; explanation about the genetic status, the type of cancer, screening and prevention of the disease. In this regard, it is important to underline that nearly half of consultees have not yet developed a cancer and also that affected members need advice about their disease free relatives or about their personal risk of developing multiple primary cancers such as bilateral breast tumors or breast and ovarian cancer in a single individual $[14,15]$. Finally, a part of the consultation is devoted to blood sample collection or to informing the proband of family members for whom blood samples are needed (76\% of cases). This applies particularly if DNA testing is planned or if the family is to be included in a research protocol. Time is also required for ascertaining the personal and/or family history of probands by obtaining authorizations of the proband and/or family members to collect medical and pathological reports (67\% of cases).

Variations in several parameters were 
observed during the 4-year period and may result from scientific breakthroughs in cancer genetics such as the identification of genes predisposing to cancer, (mainly breast cancer, the most frequent site involved in our study) and the consequent transfer of this scientific knowledge to clinical practice (genetic testing). Thus, for linkage analyses $[16,17]$ numerous blood samples (from unaffected family members and/or male relatives such as father and brothers) were needed to establish the genetic phases until major genes such as BRCA1 [18] and BRCA2 [19] were identified in 1994 and 1995. Then, the majority of tests involved affected women, to establish the genetic basis of the familial aggregation and/or for research purposes (penetrance, mutation spectrum, founder effect). Actually, since numerous mutations have already been identified in affected women, an increasing number of samples are now being collected from unaffected relatives, including male patients, for genetic testing. We observed, for example, a variation of the mean number of blood samples collected when a male attends the cancer genetic clinics (data not shown; $p=0.003$ ), with a decrease from 1994 to 1996 (from 7 to 1 individual samples collected), and then an increase from 1996 to 1997 (from 1 to 2 individual samples collected).

In addition, these changes from one year to another may reflect modification of medical practices. For instance, changes in the proportion of consultations that involved establishing the genetic status of patients may be explained by the increasing number of consultations devoted to the follow up of individuals from known families and by the availability of DNA testing. Another consideration is that, while cancer centers still account for the majority of consultations, more patients are now seen in other institutions. The increasing number of patients with a personal and/or a family history of colon cancer, seen mainly in institutions other than cancer centers, may reflect this evolution.

Finally, since duration of consultations (more or equal to 1 hour), personal or family history of breast/ovarian cancer, appeared as pivotal elements in our study and thus may affect the organization of clinics, and consequently the evolution of cancer genetic activity in France, we analyzed more precisely the factors significantly associated with these 2 elements. First, a consultation with a duration of 1 hour or more is correlated with the first visit of a new family (mainly of breast cancer) with the ascertainment of diagnosis of tumor cases, as well as with counseling patients about prevention and screening, and with the existence of a genetic predisposition. Second, when breast or ovarian cancer is the motif of the consultation, the consultees are predominantly women, a genetic predisposition is frequently considered, the consultation takes a longer time and these patients are mainly seen in cancer centers.

Interestingly, more than $20 \%$ of patients were enrolled in research protocols and this element did not affect the duration of the consultation. Thus, during the period of analysis several scientific cooperations were set up at the national or at the international level and the French cooperative network was involved as a whole or through individual participation. Research programs were developed mainly on hereditary breast cancers: on molecular aspects by linkage analysis or mutation search [12,20-22]; genetic heterogeneity, analysis of penetrance, and genotype-phenotype correlations [23-25]; natural history prognosis and morphoclinical aspects [26,27]; and BRCA1 mutation screening strategies $[28,29]$. In addition, programs were also developed on public health and sociological aspects of cancer genetics: expectations of patients [30,31], impact of consultations [32-34], acceptability of genetic tests $[35,36]$ and acceptability of strategies to deal with hereditary breast and ovarian cancer to patients [37-39] and to physicians $[40,41]$.

Finally, all these research programs and the present study are precious elements to help and to guide the organization of cancer genetic activity at the national level. One of the aims is to avoid the development of heterogeneous medical practices which may be the result of the large population involved and of the geographical dispersion of cancer genetic clinics. With this objective, recommendations on the organization of cancer genetic consultations [13] and 
recommendations for medical management of individuals at high risk of cancer [7,42] were established at the national level.

\section{Participants: The French Cooperative Network}

D. Serin (Clinique Sainte Catherine, Avignon); V. Laithier, (CHU J. Minjoz, Besançon); A. Rossi (CTS, Bois-Guillaume); M. Longy, C. Toulouse (Institut Bergonié, Bordeaux); P. Berttet, A. Hardouin (Centre F. Baclesse, Caen); V. Chamouton (CHG, Chalon s/Saone); O. Bay, M. Petit (Centre J. Perrin, Clermon-Ferrand); C. Belichard (Centre G.-F. Leclerc, Dijon); D. Leroux, M. Mousseau (CHU et Université de Grtenoble, Grenoble); C. Buffet, V. Boige (CHU, Le Kremlin-Bicètre); D. Martin-Coignard (CHG, Le Mans); P. Vennin (Centre O. Lambret, Lille); B. Gilbert (CHU, Limoge); F. Desseigne, D. Frappaz, H. Mignotte (Centre L. Bérard, Lyon); A.-M. Capodano (CHU, Marseille); P. Pujol (CHU, Montpellier); M. Ychou (Centre Val d'Aurel, Montpellier); M. Frenay, J Gioanni (Centre A. Lacassagne, Nice); P. Gesta (CHG, Niort); F. Soubrier (Hôpital Tenon, Paris); S. Olschwang (CEPH, Paris); P. Laurent-Puig (Hôpital Laennec, Paris) O. Cohen-Haguenauer (Hôpital Saint Louis, Paris); K. Zummer (Sce Prévention et Dépistage de la ville de Paris, Paris); D. Bonneau (CHU, Poitier); L. Demange, B. Maes (Institut J. Godinot, Reims); D. Guerrin, A. Mercier-Blas, V. Quillien-Pouvreau (Centre E. Marquis, Rennes); B. Delpech (Centre H. Becquerel, Rouen); A. Chevrier, T. Frebourg (CHU, Rouen); C. Maugard (Centre R. Huguenin, Saint-Herblain); J.-M. Limacher (CHU, Strasbourg); J.-P. Fricker, S. Schraub (Centre P. Strauss, Strasbourg); R. Guimbaud, M. Machelard (Centre C. Regaud, Toulouse); P. Bougnoux (CHU, Tours); E. Luporsi (Centre A. Vautrin, Vandoeuvre-les-Nancy); B. Leheup, D. Sommelet (CHU, Vandoeuvre-les-Nancy); M.-F. Avril, L. Brugière, A. Chompret, N. Janin, M. Schlumberger (Institut G. Roussy, Villejuif).

\section{Acknowledgments}

We are particularly indebted to patients and their families. We are grateful to Fédération Nationale des Centres de Lutte Contre le Cancer and to La Ligue Nationale Contre le Cancer. We thank Laetitia Rabayrol for assitance in statistical analyses.

\section{References}

[1] Lindor, N., Greene, M. and the Mayo Familial Cancer Program. The concise handbook of family cancer syndromes. J. Natl. Cancer. Inst. 90, (1998) 1039-1071.

[2] Knudson, A.G. Antioncogenes and human cancer. Proc. Natl. Acad. Sci. USA. 90, (1993) 10914-10921.

[3] Kinzler, K. and Vogelstein, B. Gatekeepers and Caretakers. Nature 386, (1997) 761-763.

[4] Ilyas, M., Strub, J., Tomlison, I. and Bodmer, W. Cancer genetic pathways in colorectal and other cancers. Eur. J. Cancer. 35, (1998) 335-351.

[5] Burke, W., Petersen, G., Lynch, P., Botkin, J., Daly, M., Garber, J., Kahn, M.J., McTiernan, A., Offit, K., Thomson, E. and Varricchio, C. Recommendations for follow-up care of individuals with an inherited predisposition to cancer. I. Hereditary nonpolyposis colon cancer. Cancer Genetics Studies Consortium. J. Am. Med. Assoc. 277, (1997) 915-919.

[6] Burke, W., Daly, M., Garber, J., Botkin, J., Kahn, M., Lynch, P., McTiernan, A., Offit, K., Perlman, J., Petersen, G., Thomson, E., Varricchio, C. and the Cancer Genetics Studies Consortium. Recommendations for Follow-up Care of Individuals With inherited Predisposition to Cancer II. BRCA1 and BRCA2. J. Am. Med. Assoc. 277, (1997) 997-1003.

[7] Eisinger, F., Alby, N., Bremond, A., Dauplat, J., Espié, M., Janiaud, P., Kutten, F., Lebrun, J.-P., Lefranc, J.-P., Pierret, J., Sobol, H., StoppaLyonnet, D., Thouvenin, D., Tristant, H. and Feingold, J. Recommendations for medical management of hereditary breast ovarian cancer : The French national Ad Hoc committee. Ann. Oncol. 9, (1998) 939-950.

[8] Eisinger, F., Nogues, C., Guinebretiere, J.-M., Peyrat, J.-P., Bardou, V.-J., Noguchi, T., Vennin, 
P., Sauvan, R., Lidereau, R., Birnbaum, D., Jacquemier, J. and Sobol, H. Novel indications for BRCA1 screening using individual clinical and morphological features. Int. J. Cancer. (Pred Oncol). 84, (1999) 263-267.

[9] Anonymous. Mise en fonctionnement d'une section d'oncologie génétique en Novembre 1998. Centres. 28, (1989) 4.

[10] Bourret, P., Julain-Reynier, C., Eisinger, F. and Sobol, H. Questions sociales et sociologiques autour de l'Oncogénétique clinique. In: J.Y. Bignon (ed.) Oncogénétique vers une médecine de présomption/prédiction. pp. 363-376. Paris: Lavoisier Tec \& Doc, 1997.

[11] Sobol, H., Bignon, Y., Cuisenier, J., StoppaLyonnet, D., Nogues, C. and Eisinger, F. Le groupe Génétique et Cancer de la FNCLCC. Les consultations d'Oncogénétique en 1994, analyse de l'activité: enquête sur 203 consultations. In: M. Boiron and M. Marty (eds.), Eurocancer 95. pp. 43-46. Paris: John Libbey Eurotext, 1995.

[12] Sobol, H., Mazoyer, S., Narod, S., Smith, S., Black, D., Kerbrat, P., Jamot, B., Solomon, E., Ponder, B. and Guerin, D. Genetic heterogeneity of early onset familial breast cancer. Hum. Genet. 89, (1992) 381-383.

[13] Eisinger, F., Thouvenin, D., Bignon, Y.J., Cuisenier, J., Feingold, J., Hoerni, B., Lasset, C., Lyonnet, D., Maraninchi, D., Marty, M., Mattei, J.F., Sobol, H., Maugard-Louboutin, C., Nogues, C., Pujol, H. and Philip, T. Réflexions sur l'organisation des consultations d'oncogénétique: première étape vers la publication de bonnes pratiques cliniques. Bull Cancer. 82, (1995) 865878.

[14] Ford, D., Easton, D.F., Bishop, D.T., Narod, S.A., Goldgar, D.E. and the Breast Cancer Linkage Consortium. Risks of cancer in BRCA1mutation carriers. Lancet 343, (1994) 692-695.

[15] Shattuck-Eidens, D., Oliphant, A., McLure, M., McBride, C., Gupte, J., Rubano, T., Pruss, D., Tagvitian, S., Teng, D., Adey, N., Staebell, M. et al. BRCA1 sequence analysis in women at high risk for susceptibility mutations: risk factor analysis and implications for genetic testing. $J$. Am. Med. Assoc. 278, (1997) 1242-1250.

[16] Hall, J., Lee, M., Morrow, J., Newman, B., Anderson, L., Huey, B. and King, M. Linkage anlysis of early onset familial breast cancer to chromosome 17q21. Science 250, (1990) 16841689.

[17] Wooster, R., Neuhausen, S.L., Mangion, J., Quirk, Y., Ford, D., Collins, N., Nguyen, K.,
Seal, S., Tran, T., Averill, D., Fields, P., Marshall, G., Narod, S., Lenoir, G.M., Lynch, H., Feunteun, J., Devilee, P., Cornelisse, C.J., Menko, F.H., Daly, P.A., Ormiston, W., McManus, R., Pye, C., Lewis, C.M., CannonAlbright, L.A., Peto, J., Ponder, B.A.J., Skolnick, M.H., Easton, D.F., Goldgar, D.E. and Stratton, M.R. Localization of a Breast Cancer Suceptibility Gene, BRCA2, to Chromosome 13q12-13. Science 265, (1994) 2088-2090.

[18] Miki, Y., Swensen, J., Shattuck-Eidens, D., Futreal, P.A., Harshman, K., Tavtigian, S., Liu, Q., Cochran, C., Bennett, L.M., Ding, W., Bell, R., Rosenthal, J., Hyssey, C., Tran, T., McClure, M., Frye, C., Hattier, T., Phelps, R., HaugenStrano, A., Katcher, H., Yakumo, K., Gholami, Z., Shaffer, D., Stone, S., Bayer, S., Wray, C., Bogden, R., Dayananth, P., Ward, J., Tonin, P., Narod, S., Bristow, P.K., Norris, F.H., Helvering, L., Morrisson, P., Rosteck, P., Lai, M., Barrett, J.C., Lewis, C., Neuhausen, S., Albright, L.C., Goldgar, D., Wiseman, R., Kamb, A. and Skolnick, M.H. A strong candidate for the breast and ovarian cancer susceptibility gene BRCA1. Science 266, (1994) 66-71.

[19] Wooster, R., Bignell, G., Lancaster, J., Swift, S., Seal, S., Mangion, J., Collins, N., Gregory, S., Gumbs, C., Micklem, G., Barfoot, R., Hamoudi, R., Patel, S., Rice, C., Biggs, P., Hashim, Y., Smith, A., Connor, F., Arason, A., Gudmundsson, J., Ficenec, D., Kelsell, D., Ford, D., Tonin, P., Bishop, T., Spurr, N., Ponder, B., Eeles, R., Peto, J., Devilee, P., Cornelisse, C., Lynch, H., Narod, S., Lenoir, G., Egilsson, V., Barkadottir, R., Futreal, P., Ashworth, A. and Stratton, M. Identification of the breast cancer susceptibility gene BRCA2. Nature 378, (1995) 789-792.

[20] Mazoyer, S., Lalle, P., Narod, S.A., Bignon, Y.J., Courjal, F., Jamot, B., Dutrillaux, B., StoppaLyonnet, D. and Sobol, H. Linkage analysis of 19 French breast cancer families, with five chromosome 17q markers. Am. J. Hum. Genet. 52, (1993) 754-760.

[21] Stoppa-Lyonnet, D., Fricker, J., Essioux, L., Pages, S., Limacher, J., Sobol, H., Laurent-Puig, P. and Thomas, G. Segregation of two BRCA1 mutations in a single family. Am. J. Hum. Gen. 59, (1996) 479-481.

[22] Essioux, L., Girodet, C., Sinilnikova, O., Pages, S., Eisinger, F., de Resende, S., Maugard, C., Lanoe, D., Longy, M., Bignon, Y.-J., Sobol, H., Bonaiti-Pellie, C. and Stoppa-Lyonnet, D. 
Marker segregation information in breast/ovarian cancer genetic counselling: is it still useful? Groupe Genetique et Cancer de la Federation Nationale des Centres de Lutte Contre le Cancer. Am. J. Med. Genet. 79, (1998) 175-183.

[23] Kerangueven, F., Essioux, L., Dib, A., Noguchi, T., Allione, F., Geneix, F., Longy, M., Lidereau, R., Eisinger, F., Pebusque, M., Jacquemier, J., Bonaiti-Pellie, C., Sobol, H. and Birnbaum, D. Loss of heterozygosity and linkage analysis in breast carcinoma: indication for a putative third susceptibility gene on the short arm of chromosome 8. Oncogene 10, (1995) 1023-1026.

[24] Ford, D., Easton, D., Stratton, M., Narod, S., Goldgar, D., Devilee, P., Bishop, D., Weber, B., Lenoir, G., Chang-Claude, J., Sobol, H., Teare, M., Struewing, J., Arason, A., Scherneck, S., Peto, J., Rebbeck, T., Tonin, P., Neuhausen, S., Barkardottir, R., Eyfjord, J., Lynch, H., Ponder, B., Gayther, S., Birch, J., Lindblom, A., StoppaLyonnet, D., Bignon, Y., Borg, A., Hamann, U., Haites, N., Scott, R., Maugard, C., Vasen, H., Seitz, S., Cannon-Albright, L., Scofield, A., Zeleda-Hedman, M. and the Breast Cancer Linkage Consortium. Genetic heterogeneity and penetrance analysis of the BRCA1 and BRCA2 genes in breast cancer families. Am. J. Hum. Genet. 62, (1998) 679-689.

[25] Sobol, H., Stoppa-Lyonnet, D., Bressac-dePaillerets, B., Peyrat, J.P., Kerangueven, F., Janin, N., Noguchi, T., Eisinger, F., Guinebretière, J.M., Jacquemier, J. and Birnbaum, D. Truncation at conserved terminal regions of BRCA1 protein is associated with highly proliferating hereditary breast cancers. Cancer Res. 56, (1996) 3216-3219.

[26] Eisinger, F., Stoppa-Lyonnet, D., Longy, M., Kerangueven, F., Noguchi, T., Bailly, C., Vincent-Salomon, A., Jacquemier, J., Birnbaum, D. and Sobol, H. Germ line mutation at BRCA1 affects the histoprognostic grade in hereditary breast cancer. Cancer Res. 56, (1996) 471-474.

[27] Eisinger, F., Jacquemier, J., Charpin, C., StoppaLyonnet, D., Bressac-de Paillerets, B., Peyrat, J.P., Longy, M., Guinebretiere, J.-M., Sauvan, R., Noguchi, T., Birnbaum, D. and Sobol, H. Mutations at BRCA1: The medullary breast carcinoma revisited. Cancer Res. 58, (1998) 1588-1592.

[28] Eisinger, F., Nogues, C., Guinebretiere, J.-M., Peyrat, J.-P., Bardou, V.-J., Noguchi, T., Vennin, P., Sauvan, R., Lidereau, R., Birnbaum, D. and Sobol, H. Novel indications for BRCA1 screening using individual clinical and morphological features. Int. J. Cancer 84, (1999) 263-267.

[29] Stoppa-Lyonnet, D., Laurent-Puig, P., Essioux, L., Pages, S., Ithier, G., Ligot, L., Fourquet, A., Salmon, R., Clough, K., Pouillart, P., The ICBCG, Bonaiti-Pellié, C. and Thomas, G. BRCA1 sequence variations in 160 individuals referred to a breast/ovarian family cancer clinic. Am. J. Hum. Genet. 60, (1997) 1021-1030.

[30] Julian-Reynier, C., Eisinger, F., Chabal, F., Aurran, Y., Nogues, C., Vennin, F., Bignon, Y., Machelard-Roumagnac, M., Maugard-Louboutin, C., Serin, D., Versini, S., Mercuri, M. and Sobol, H. Cancer genetics clinics: Target population and consultees' expectations. Eur. J. Cancer 32A, (1996) 398-403.

[31] Julian-Reynier, C., Eisinger, F., Chabal, F., Aurran, Y., Bignon, Y.-J., Noguès, C., Maugard, C., Machelard, M., Vennin, P. and Sobol, H. Cancer genetic clinics: why do women who already have cancer attend? Eur. J. Cancer 34, (1998) 1549-1553.

[32] Julian-Reynier, C., Eisinger, F., Chabal, F., Aurran, Y., Nogues, C., Vennin, P., Bignon, Y.J., Machelard, M., Maugard, C. and Sobol, H. Consultations d'oncogénétique: attentes et impact sur l'état d'anxiété des patientes atteintes de cancer du sein. Rev. Epid. Santé Pub. 45, (1997) S32.

[33] Julian-Reynier, C., Eisinger, F., Chabal, F., Aurran, Y., Bignon, Y.-J., Nogues, C., Machelard, M., Vennin, P. and Sobol, H. Time elapsing from cancer diagnosis and anxiety in women attending cancer genetic clinics. Oncol. Report 5, (1998) 885-888.

[34] Julian-Reynier, C., Eisinger, F., Chabal, F., Aurran, Y., Bignon, Y.-J., MachelardRoumagnac, M., Maugard, C., Noguès, C., Vennin, P. and Sobol, H. Cancer genetic consultation and anxiety feelings in healthy consultees. Psychology Health. 14, (1999) 379390.

[35] Julian-Reynier, C., Eisinger, F., Vennin, F., Chabal, F., Aurran, Y., Nogues, C., Bignon, Y., Machelard-Roumagnac, M., Maugard-Louboutin, C., Serin, D., Blanc, B., Orsoni, P. and Sobol, H. Attitudes towards cancer predictive testing and transmission of information to the family. J. Med. Genet. 33, (1996) 731-736.

[36] Julian-Reynier, C., Eisinger, F., Chabal, F., Aurran, Y., Noguès, C., Vennin, P., Bignon, Y., Roumagnac, M., Maugard-Louboutin, C., 
Versini, S., Serin, D., Michel, J. and Sobol, H. Attitudes des consultantes vis-à-vis du diagnostic prédictif de cancer du sein et de la diffusion d'information dans la famille. Bull Cancer 83, (1996) 458.

[37] Eisinger, F., Julian-Reynier, C., Chabal, F., Luquet, C., Moatti, J.P. and Sobol, H. Acceptable strategies for dealing with hereditary breast/ovarian cancer risk. J. Natl. Cancer. Inst. 89, (1997) 731.

[38] Eisinger, F., Julian-Reynier, C., Chabal, F., Stoppa-Lyonnet, D., Lasset, C., Nogues, C., Vennin, P. and Sobol, H. Consultees' opinions about the preventive options avaible for hereditary breast cancers: a French national survey. Am. J. Hum. Gen. 61(S), (1997) A188.

[39] Eisinger, F., Julian-Reynier, C., Stoppa-Lyonnet, D., Vennin, P., Lasset, C., Noguès, C. and Sobol, $\mathrm{H}$. Breast and ovarian cancer prone women and prophylactic surgery temptation. J. Clin. Oncol. 16, (1998) 2573-2575.
[40] Vennin, P., Giard, S., Julian-Reynier, C., Sailly, F., Peyrat, J.P., Fournier, C., Eisinger, C. and Sobol, H. Attitudes envers le dépistage et la prévention des cancers mammaires et ovariens avec prédisposition héréditaire. Enquête auprès des femmes gynécologues de la région Nord de la France. Bull Cancer 83, (1996) 697-702.

[41] Julian-Reynier, C., Eisinger, F., Aurran, Y., Chabal, F. and Sobol, H. Attitudes about breast cancer genetics and preventive strategies: a national survey of French medical and surgical gynecologists. Am. J. Hum. Genet. 61(S), (1997) A222.

[42] Eisinger, F., Espié, M., Kuttenn, F., Lasset, C., De Lignières, B., Namer, M., Roché, H., Sasco, A., Serin, D. and Philip, T. La chimioprévention du cancer du sein: Prise de position au 3 Juillet 1998 de la Fédération Nationale des Centres de Lutte Contre le Cancer (FNCLCC). Bull Cancer 85, (1998) 725. 


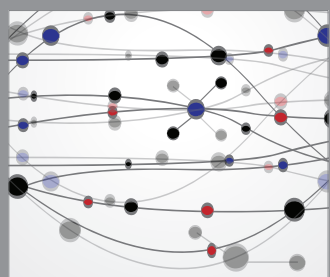

The Scientific World Journal
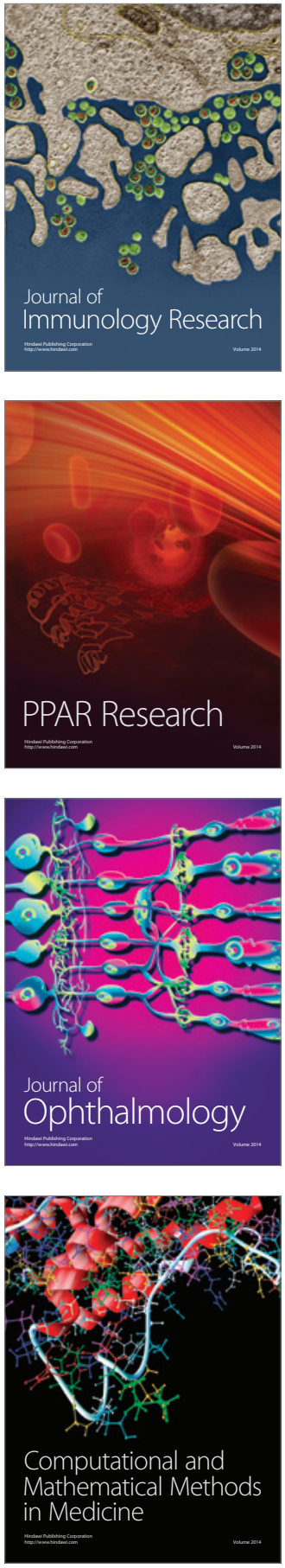

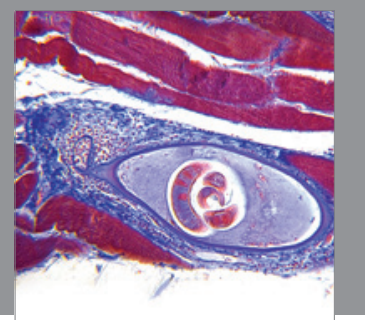

Gastroenterology

Research and Practice
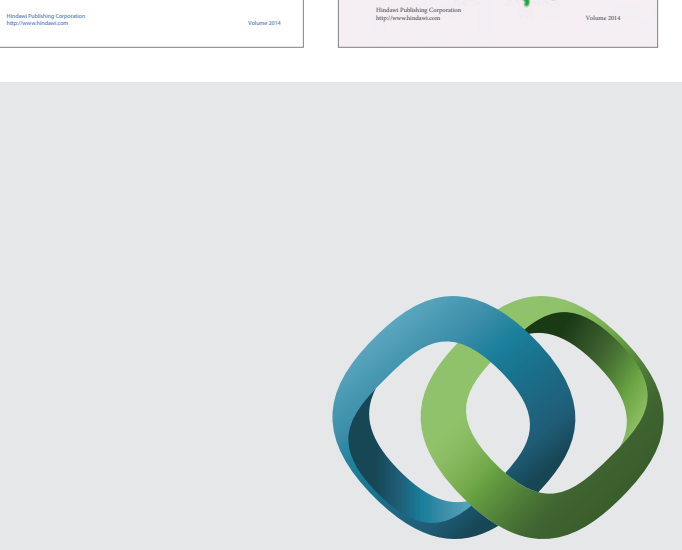

\section{Hindawi}

Submit your manuscripts at

http://www.hindawi.com
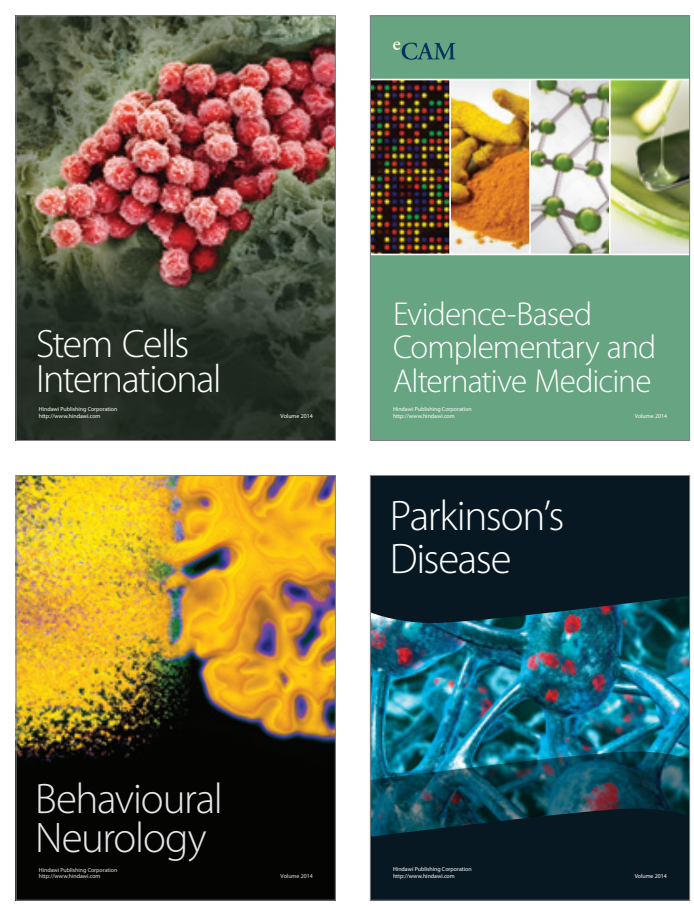

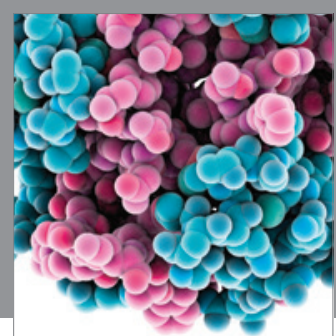

Journal of
Diabetes Research

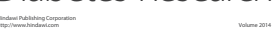

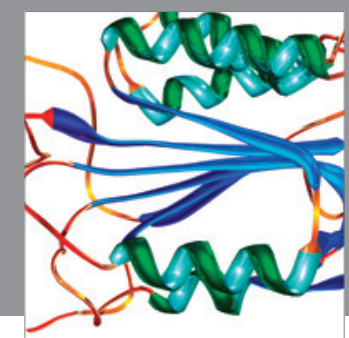

Disease Markers
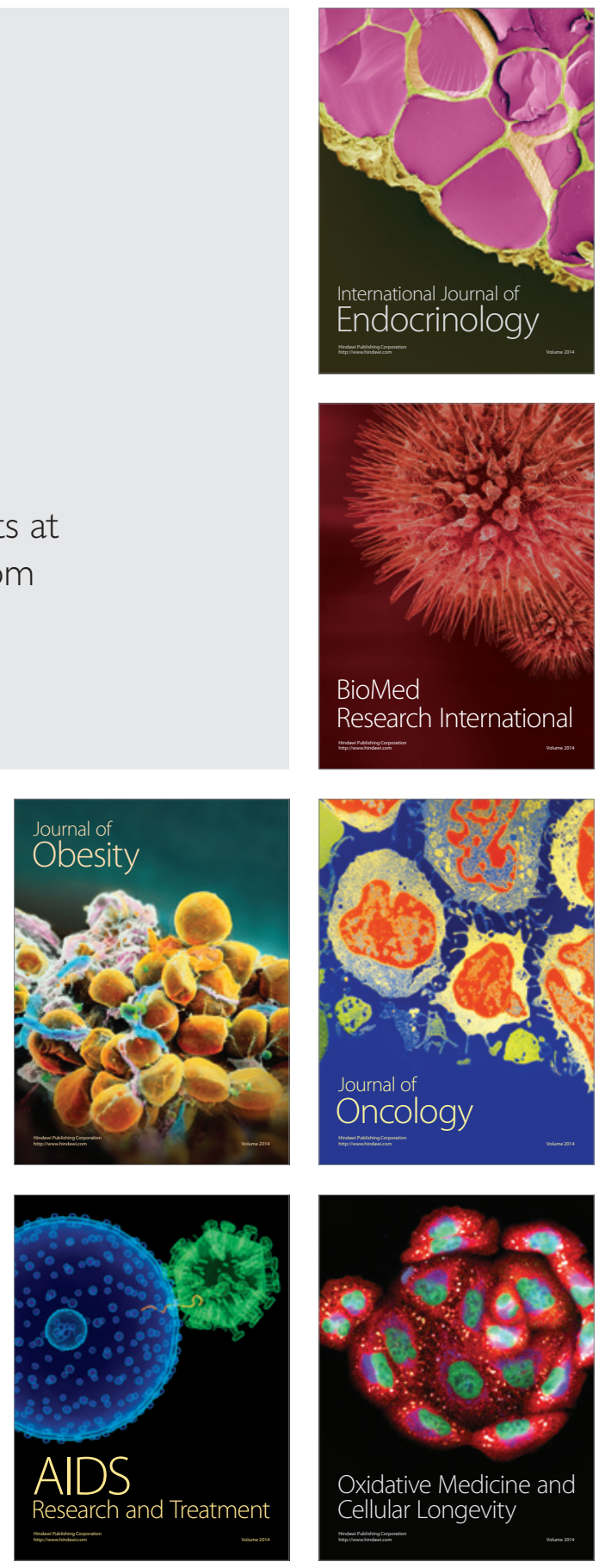